\title{
Perencanaan Instalasi Pengolahan Air Limbah (IPAL) di Rumah Susun Tanah Merah Surabaya
}

\author{
Daneswari Mahayu Wisesa dan Agus Slamet \\ Jurusan Teknik Lingkungan, Fakultas Teknik Sipil dan Perencanaan, Institut Teknologi Sepuluh \\ Nopember (ITS) \\ Jl. Arief Rahman Hakim, Surabaya 60111 Indonesia \\ e-mail:suga@its.ac.id
}

\begin{abstract}
Abstrak - Kegiatan rumah tangga pada Rumah Susun Tanah Merah menghasilkan air limbah domestik yang terdiri dari greywater dan blackwater. Greywater pada Rumah Susun Tanah Merah langsung dibuang ke drainase tanpa melalui proses pengolahan. Sedangkan blackwater diolah pada Instalasi Pengolahan Air Limbah (IPAL) eksisting, namun efluen yang dihasilkan masih belum memenuhi baku mutu. Di sisi lain, warga Rumah Susun Tanah Merah mengalami kekurangan air untuk kegiatan sehari-hari. Instalasi Pengolahan Air Limbah dibutuhkan untuk mengolah air limbah domestik menjadi air olahan yang dapat dimanfaatkan kembali. Pada perencanaan ini dilakukan perhitungan air limbah domestik yang dihasilkan oleh penghuni Rumah Susun Tanah Merah. Selain itu dilakukan analisis karakteristik greywater dan blackwater. Debit dan karakteristik air limbah domestik tersebut menjadi acuan dalam perhitungan IPAL. Unit IPAL yang digunakan yaitu Grease Trap, Anaerobic Baffle Reactor (ABR) dan Aerobic Biofilter. Grease Trap yang direncanakan memiliki efisiensi penyisihan minyak dan lemak mencapai 95\%. Sedangkan Anerobic Baffle Reactor dan Aerobic Biofilter memiliki efisiensi penyisihan BOD, COD, TSS berturut turut adalah 99,5\%, 98,8\%, dan 99\%. Air hasil olahan ditampung pada bak penampung dan dapat dimanfaatkan kembali oleh penghuni Rumah Susun Tanah Merah untuk menyiram tanaman dan sebagai air penggelontor.
\end{abstract}

Kata Kunci-Aerobic Biofilter, Anaerobic Baffle Reactor, Grease Trap

\section{PENDAHULUAN}

$\mathrm{R}$ UMAH Susun Tanah Merah merupakan salah satu rumah susun yang dikelola oleh Pemerintah Kota Surabaya. Kegiatan rumah tangga di Rumah Susun Tanah Merah akan menghasilkan air limbah domestik. Air limbah domestik terdiri dari dua jenis, yaitu greywater dan blackwater [1]. Greywater berasal dari buangan kamar mandi, dapur dan pencucian, sedangkan blackwater berasal dari buangan toilet (tinja dan urin).

Rumah Susun Tanah Merah memiliki Instalasi Pengolahan Air Limbah (IPAL) untuk mengolah blackwater, namun efluen yang dihasilkan masih belum memenuhi baku mutu. Sedangkan greywater langsung dialirkan ke drainase tanpa diolah. Hal tersebut dapat meningkatkan beban pencemaran pada badan air [3].

Air limbah domestik merupakan penyumbang terbesar terhadap pencemaran di badan air [4]. Air limbah domestik memberikan kontribusi sebesar $60 \%$ terhadap pencemaran di
Kali Surabaya [5]. Oleh karena itu, air limbah domestik harus diolah hingga memenuhi baku mutu sebelum dibuang ke badan air.

Di sisi lain, penghuni Rumah Susun Tanah Merah mengalami kekurangan air pada setiap hari. Hal ini dikarenakan air PDAM hanya mengalir selama 4 jam per hari, yaitu saat pagi dan sore. Berdasarkan kondisi tersebut, maka perlu dicari sumber air lain yang dapat digunakan untuk memenuhi kebutuhan air penghuni Rumah Susun Tanah Merah. Instalasi Pengolahan Air Limbah (IPAL) direncanakan untuk daur ulang air limbah domestik menjadi air yang dapat dimanfaatkan kembali. Air hasil olahan tersebut akan dimanfaatkan untuk menyiram tanaman dan sebagai air penggelontor.

\section{METODE PERENCANAAN}

Penjelasan dari metode perencanaan tersebut yaitu:

\section{A. Survei Pendahuluan}

Pada tahap survei pendahuluan, dilakukan pengamatan langsung di Rumah Susun Tanah Merah Surabaya, sehingga diperoleh gambaran mengenai permasalahan yang ada.

\section{B. Ide Perencanaan}

Berdasarkan permasalahan yang terdapat di lapangan, maka dapat diperoleh ide perencanaan, yaitu "Perencanaan Instalasi Pengolahan Air Limbah di Rumah Susun Tanah Merah Surabaya"

\section{Studi Literatur}

Pelaksanaan studi literatur bertujuan untuk menunjang konsep dan teori dalam melaksanakan perencanaan. Literatur yang dipelajari antara lain mengenai debit air limbah domestik, karakteristik greywater, karakteristik blackwater, baku mutu air limbah domestik, baku mutu air permukaan kelas satu, Sistem Penyaluran Air Limbah (SPAL), grease trap, anaerobic baffle reactor serta aerobic biofilter.

\section{Pengumpulan Data}

Data yang dikumpulkan terdiri dari data primer dan sekunder. Data primer diperoleh dari hasil pengamatan langsung di lapangan. Sedangkan data sekunder diperoleh dari hasil wawancara, data instansi terkait, serta literatur yang relevan. 
Data primer yang dibutuhkan meliputi debit blackwater, karakteristik greywater, karakteristik blackwater, luas lahan yang tersedia, elevasi tanah, jaringan perpipaan eksisting. Sedangkan data sekunder yang dibutuhkan meliputi jumlah unit dan jumlah penghuni Rumah Susun Tanah Merah, debit penggunaan air bersih, debit blackwater dari literatur, dan baku mutu air permukaan kelas satu.

\section{E. Analisis dan Pembahasan}

Analisis dan pembahasan yang dilakukan meliputi dua aspek, yaitu aspek teknis dan aspek finansial. Aspek teknis meliputi:

- Perhitungan debit greywater dan blackwater yang dihasilkan

- Analisis karakteristik greywater dan blackwater

- Penentuan baku mutu yang digunakan, yaitu mengacu pada baku mutu air permukaan kelas satu yang tercantum pada Peraturan Pemerintah Nomor 82 Tahun 2001

- Analisis kondisi Instalasi Pengolahan Limbah (IPAL) eksisting

- Perencanaan Detail Engineering Design (DED) pada masing-masing unit IPAL yang akan digunakan

- Perencanaan Sistem Penyaluran Air Limbah (SPAL)

Sedangkan aspek finansial meliputi perhitungan biaya yang dibutuhkan untuk konstruksi SPAL dan IPAL yang direncanakan. Perhitungan pada aspek finansial mengacu pada Harga Satuan Pokok Kegiatan (HSPK) Kota Surabaya Tahun 2015.

\section{F. Kesimpulan dan Saran}

Kesimpulan diperoleh dari hasil analisis, sedangkan saran dibuat sebagai referensi perencanaan berikutnya.

\section{HASIL DAN PEMBAHASAN}

\section{A. Gambaran Umum Wilayah Perencanaan}

Rumah Susun Tanah Merah terletak di Jalan Tanah Merah V, Kelurahan Tanah Kali Kedinding, Kecamatan Kenjeran, Surabaya. Rumah Susun Tanah Merah terdiri dari Rumah Susun Tanah Merah 1 dan 2. Rumah Susun Tanah Merah 1 terdiri dari 4 gedung, yaitu Gedung A, Gedung B, Gedung C, dan Gedung D. Sedangkan Rumah Susun Tanah Merah 2 terdiri dari 2 gedung, yaitu Gedung A dan Gedung B.

Rumah Susun Tanah Merah 1 memiliki 192 unit. Apabila seluruh unit terisi penuh, maka jumlah penghuni pada Rumah Susun Tanah Merah 1 sebanyak 768 jiwa. Sedangkan Rumah Susun Tanah Merah 2 memiliki 196 unit. Jika seluruh unit pada Rumah Susun Tanah Merah 2 terisi penuh, maka jumlah penghuninya sebanyak 784 jiwa.

Berdasarkan data rekening air bersih yang diperoleh selama 4 bulan, dapat diketahui bahwa kebutuhan air bersih untuk seluruh penghuni Rumah Susun Tanah Merah sebesar 90,03 $\mathrm{m}^{3} /$ hari. Sehingga dapat dihitung bahwa kebutuhan rata-rata air bersih setiap penghuni Rumah Susun Tanah Merah sebesar 121 L/orang.hari.

Pada Rumah Susun Tanah Merah 1 telah terdapat jaringan perpipaan vertikal (plumbing) yang terpisah antara greywater dan blackwater. Greywater dialirkan secara langsung ke drainase tanpa diolah. Sedangkan blackwater diolah pada tangki septik eksisting. Tangki septik eksisting pada Rumah Susun Tanah Merah 1 sebanyak 2 buah. Supernatan dari hasil pengolahan tangki septik dialirkan ke drainase, sedangkan lumpur yang dihasilkan tidak pernah dikuras. Berdasarkan hal tersebut, maka dapat disimpulkan bahwa tangki septik mengalami kebocoran, sehingga tidak dapat digunakan lagi.

Pada Rumah Susun Tanah Merah 2 juga terdapat jaringan perpipaan vertikal (plumbing) yang terpisah antara greywater dan blackwater. Greywater langsung dialirkan ke drainase tanpa melalui proses pengolahan. Sedangkan blackwater diolah pada Aerobic Baffle Reactor (ABR) eksisting. Pada Rumah Susun Tanah Merah 2 terdapat 4 unit ABR. Supernatan yang dihasilkan dari proses pengolahan dialirkan ke drainase, namun kualitasnya masih belum memenuhi baku mutu air limbah domestik. Sedangkan pada lumpur dilakukan pengurasan.

\section{B. Debit Air Limbah Domestik}

Debit air limbah domestik diperkirakan sebesar $80 \%$ dari debit penggunaan air bersih, yaitu sebesar 97 L/orang.hari. Berdasarkan hasil survei, diperoleh debit blackwater sebesar 26 L/orang.hari, nilai tersebut telah sesuai dengan literaturliteratur yang diperoleh. Debit greywater dapat dihitung dengan cara mencari selisih antara debit air limbah domestik dengan debit blackwater, yaitu sebesar 71 L/orang.hari.

Jumlah penghuni Rumah Susun Tanah Merah sebanyak 1552 jiwa, sehingga diperoleh faktor puncak sebesar 1,3. Debit air limbah puncak dapat diperoleh dengan mengalikan debit air limbah rata-rata dengan faktor puncak. Debit puncak air limbah untuk seluruh unit rumah susun adalah $198,7 \mathrm{~m}^{3} / \mathrm{hari}$.

\section{Karakteristik Air Limbah Domestik}

Karakteristik air limbah domestik dapat diketahui dengan cara pengambilan sampel dan analisa sampel di laboratorium. Sampel air limbah domestik yang dianalisa meliputi greywater, blackwater influen ABR eksisting, serta blackwater efluen ABR eksisting. Pengambilan sampel pada titik influen dan efluen ABR bertujuan untuk mengetahui efisiensi ABR eksisting tersebut. Kualitas blackwater yang belum diolah diasumsikan sama dengan kualitas influen ABR eksisting.

Parameter greywater yang dianalisa meliputi BOD, COD, TSS, minyak dan lemak. Sedangkan parameter blackwater yang dianalisa meliputi BOD, COD, TSS, dan total coliform. Hasil analisa karakteristik air limbah domestik ditunjukkan pada Tabel 1. 
Tabel 1. Karakteristik Air Limbah Domestik

\begin{tabular}{lccc}
\hline \hline \multicolumn{1}{c}{ Parameter } & $\begin{array}{c}\text { Greywate } \\
r\end{array}$ & $\begin{array}{c}\text { Blackwater } \\
\text { Influen ABR }\end{array}$ & $\begin{array}{c}\text { Blackwater } \\
\text { Efluen ABR }\end{array}$ \\
\hline BOD (mg/L) & 147 & 1023 & 185 \\
COD (mg/L) & 320 & 1211 & 215 \\
TSS (mg/L) & 320 & 1153 & 253 \\
Minyak dan Lemak (mg/L) & 29 & 0 & 0 \\
$\begin{array}{l}\text { Total coliform (Jml/100 } \\
\text { ml) }\end{array}$ & 0 & 26000 & 9000 \\
\hline \hline
\end{tabular}

\section{Analisa Kondisi ABR Eksisting}

Pada Rumah Susun Tanah Merah 2 terdapat 4 unit ABR, yaitu ABR A, ABR B, ABR C, dan ABR D. ABR A dan ABR $\mathrm{B}$ masing-masing mengolah blackwater dari 50 unit kamar, atau setara dengan $6,88 \mathrm{~m}^{3}$ blackwater/hari. Sedangkan ABR $\mathrm{C}$ dan ABR D masing-masing mengolah blackwater dari 48 unit kamar, atau setara dengan $6,605 \mathrm{~m}^{3}$ blackwater/hari.

Berdasarkan kualitas influen dan efluen ABR yang tercantum pada Tabel 1, maka dapat diketahui efisiensi ABR untuk menyisihkan beberapa parameter polutan, sebagai berikut:

- Efisiensi penyisihan BOD $=81,2 \%$

- Efisiensi penyisihan COD $=82,25 \%$

- Efisiensi penyisihan TSS $=78,06 \%$

- Efisiensi penyisihan total coliform $=65,38 \%$

Sedangkan efisiensi ABR menurut referensi [6] yaitu:

- Efisiensi penyisihan BOD $=70 \%-95 \%$

- Efisiensi penyisihan COD $=65 \%-90 \%$

- Efisiensi penyisihan TSS $\leq 90 \%$

Efisiensi ABR eksisting di Rumah Susun Tanah Merah 2 masih memenuhi kriteria desain sesuai literatur, sehingga dapat disimpulkan bahwa ABR eksisting akan tetap digunakan untuk pengolahan air limbah. Namun, frekuensi pengurasan harus ditingkatkan, yaitu maksimal selama 2 tahun sekali, sehingga efisiensi ABR masih dapat memenuhi target perencanaan yang diharapkan. Efluen ABR eksisting masih belum memenuhi baku mutu sesuai Peraturan Gubernur Jawa Timur Nomor 72 Tahun 2013. Pengolahan lanjutan diperlukan untuk meningkatkan kualitas air hasil olahan sehingga dapat dimanfaatkan kembali.

\section{E. Perencanaan IPAL}

IPAL pada Rumah Susun Tanah Merah 1 direncanakan menggunakan grease trap untuk mengolah greywater. Sedangkan blackwater diolah pada ABR dan aerobic biofilter bersama dengan efluen grease trap. Skema pengolahan air limbah pada Rumah Susun Tanah Merah 1 ditunjukkan pada Gambar 2.

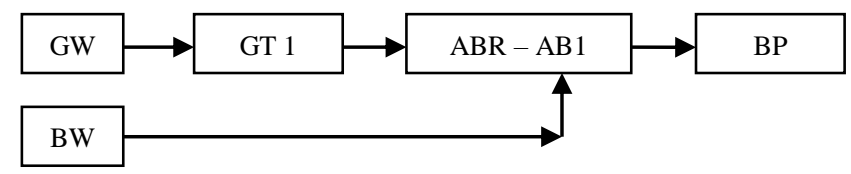

Gambar 2. Skema Pengolahan Air Limbah di Rumah Susun Tanah Merah 1

\section{Keterangan : \\ - BW \\ : Greywater \\ GT 1 \\ : Blackwater \\ : Grease Trap 1 \\ - ABR-AB 1 : Anaerobic Baffle Reactor dan Aerobic Biofilter 1 \\ - BP $\quad$ : Bak penampung air hasil olahan}

Berdasarkan skema tersebut, maka dapat dilakukan perhitungan terhadap masing-masing unit IPAL. Berikut merupakan hasil perhitungannya:

1) Grease Trap 1

- Debit influen $=71,9 \mathrm{~m}^{3} /$ hari

- Konsentrasi minyak dan lemak influen $=29$ $\mathrm{mg} / \mathrm{L}$

- Efisiensi penyisihan minyak dan lemak $=95 \%$ [7]

- Konsentrasi minyak dan lemak efluen $=1,45$

- $\mathrm{mg} / \mathrm{L}$

- Waktu detensi = $15 \mathrm{menit} /$ kompartemen [8]

- Jumlah kompartemen = 2 kompartemen

- Kedalaman efektif $=1 \mathrm{~m}$

- Lebar per kompartemen =0,6 m

- Panjang per kompartemen $=1,2 \mathrm{~m}$

2) Anaerobic Baffle Reactor - Aerobic Biofilter 1

- Debit influen $=98,3 \mathrm{~m} 3 / \mathrm{hari}$

- BOD influen $=382 \mathrm{mg} / \mathrm{L}$

- Efisiensi penyisihan $\mathrm{BOD}=99,5 \%$

- BOD efluen $=2 \mathrm{mg} / \mathrm{L}$

- COD influen $=559 \mathrm{mg} / \mathrm{L}$

- Efisiensi penyisihan COD $=98,7 \%$

- COD efluen $\quad=7,3 \mathrm{mg} / \mathrm{L}$

- TSS influen $=544 \mathrm{mg} / \mathrm{L}$

- Efisiensi penyisihan TSS $=99 \%$

- TSS efluen $=5,7 \mathrm{mg} / \mathrm{L}$

- Minyak dan lemak influen $=1,1 \mathrm{mg} / \mathrm{L}$

- Efisiensi penyisihan minyak dan lemak $=85 \%$

- Minyak dan lemak efluen $=0,2 \mathrm{mg} / \mathrm{L}$

- Total coliform influen $=6986 \mathrm{Jml} / 100 \mathrm{ml}$

- Efisiensi penyisihan total coliform $=90 \%$

- Total coliform efluen $=699 \mathrm{mg} / \mathrm{L}$

- Lebar reaktor $=2 \mathrm{~m}$

- Kedalaman efektif reaktor $=2,7 \mathrm{~m}$

- Panjang bak pengendap $=3,7 \mathrm{~m}$

- Panjang per kompartemen $=1,5 \mathrm{~m}$

- Jumlah kompartemen $=5$ kompartemen

- Panjang ruang aerasi $=2,1 \mathrm{~m}$

- Media yang digunakan adalah PVC sarang tawon, Dengan panjang media $2,1 \mathrm{~m}$, lebar media $2 \mathrm{~m}$, dan kedalaman media sebesar $1,8 \mathrm{~m}$

- Kebutuhan udara untuk aerasi $=384 \mathrm{~L} /$ menit

- Diffuser yang digunakan adalah tipe perforated pipe

- Blower yang dibutuhkan sebanyak 2 buah, dengan kapasitas masing-masing sebesar $200 \mathrm{~L} /$ menit 
IPAL Rumah Susun Tanah Merah 2 direncanakan menggunakan grease trap untuk mengolah greywater. ABR eksisting tetap dimanfaatkan untuk mengolah blackwater. Efluen dari grease trap dan ABR eksisting kemudian diolah pada aerobic biofilter. Air hasil olahan kemudian ditampung pada bak penampung. Skema pengolahan air limbah pada Rumah Susun Tanah Merah 2 ditunjukkan pada Gambar 3.

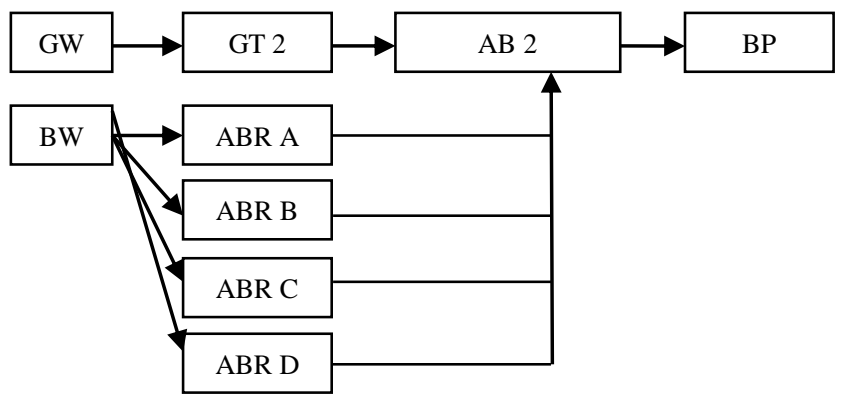

Gambar 3. Skema Pengolahan Air Limbah di Rumah Susun Tanah Merah 2

Keterangan :

- BW

: Greywater

- GT 2

: Blackwater

- ABR A,B,C,D : Anaerobic Baffle Reactor eksisting

- AB 2 : Aerobic Biofilter 2

- BP : Bak penampung air hasil olahan

Berdasarkan skema tersebut, maka dapat dilakukan perhitungan terhadap masing-masing unit IPAL. Berikut merupakan hasil perhitungannya:

1) Grease Trap 2

- Debit influen $=73,4 \mathrm{~m} 3 /$ hari

- Konsentrasi minyak dan lemak influen $=29 \mathrm{mg} / \mathrm{L}$

- Efisiensi penyisihan minyak dan lemak $=95 \%$ [7]

- Konsentrasi minyak dan lemak efluen = 1,45 mg/L

- Waktu detensi = 15 menit/kompartemen [8]

- Jumlah kompartemen $=2$ kompartemen

- Kedalaman efektif $=1 \mathrm{~m}$

- Lebar per kompartemen =0,6 m

- Panjang per kompartemen =1,2 m

2) Aerobic Biofilter 2

- Debit influen $=100,4 \mathrm{~m} 3 /$ hari

- BOD influen $=157 \mathrm{mg} / \mathrm{L}$

- Efisiensi penyisihan $\mathrm{BOD}=98,7 \%$

- BOD efluen $=2 \mathrm{mg} / \mathrm{L}$

- COD influen $=292 \mathrm{mg} / \mathrm{L}$

- Efisiensi penyisihan COD $=96,3 \%$

- COD efluen $=11 \mathrm{mg} / \mathrm{L}$

- TSS influen $=302 \mathrm{mg} / \mathrm{L}$

- Efisiensi penyisihan TSS $=90 \%$

- $\quad$ TSS efluen $=30 \mathrm{mg} / \mathrm{L}$

- Minyak dan lemak influen = 1,1 mg/L

- Efisiensi penyisihan minyak dan lemak $=85 \%$

- Minyak dan lemak efluen =0,2 mg/L

- Total coliform influen $=2418 \mathrm{Jml} / 100 \mathrm{ml}$
- Efisiensi penyisihan total coliform $=75 \%$

- Total coliform efluen $=605 \mathrm{mg} / \mathrm{L}$

- Lebar reaktor $=2 \mathrm{~m}$

- Kedalaman efektif reaktor $=2,7 \mathrm{~m}$

- Panjang ruang aerasi $=2,2 \mathrm{~m}$

- Media yang digunakan adalah PVC sarang tawon,

- Dengan panjang media $2,1 \mathrm{~m}$, lebar media $2 \mathrm{~m}$, dan kedalaman media sebesar $1,8 \mathrm{~m}$

- Kebutuhan udara untuk aerasi = $891 \mathrm{~L} /$ menit

- Diffuser yang digunakan adalah tipe perforated pipe

- Blower yang dibutuhkan sebanyak 2 buah, dengan kapasitas masing-masing sebesar 500 L/menit

Air hasil olahan dari Rumah Susun Tanah Merah 1 dan 2 selanjutnya ditampung pada bak penampung untuk dimanfaatkan kembali oleh penghuni rumah susun. Hasil perhitungan bak penampung adalah sebagai berikut:

- Waktu penampungan $=8 \mathrm{jam}$

- Lebar bak = $5 \mathrm{~m}$

- Panjang bak =4,9 m

- Kedalaman efektif $=2,7 \mathrm{~m}$

F. Perencanaan SPAL

Perencanaan SPAL dimulai dari pembuatan jaringan pipa SPAL yang mengubungkan masing-masing pipa plambing pada setiap unit kamar menuju ke IPAL. SPAL juga direncanakan untuk mengalirkan air limbah dari satu unit IPAL ke unit IPAL yang lain. Diameter pipa SPAL yang digunakan pada perencanaan ini adalah 4". Diameter tersebut sesuai dengan diameter minimal pipa penyaluran air buangan, sehingga diharapkan tidak ada padatan yang tersangkut pada pipa.

Kedalaman penanaman pipa SPAL pada titik paling akhir yang menuju ke bak penampung sebesar 0,35 meter. Kedalaman tersebut telah memenuhi kriteria desain penanaman pipa SPAL, yaitu maksimal 7 meter. Kecepatan minimal air limbah di dalam pipa direncanakan lebih dari 0,6 $\mathrm{m}$ /detik agar air limbah dapat mengalir dengan lancar, sehingga mengurangi kemungkinan timbulnya padatan.

\section{G. Rencana Anggaran Biaya (RAB)}

Rencana Anggaran Biaya (RAB) yang dibutuhkan untuk konstruksi SPAL dan IPAL sebesar Rp 1.178.316.000,00 seperti rincian pada Tabel 2.

\section{KESIMPULAN/RINGKASAN}

Berdasarkan perhitungan yang telah dilakukan, maka dapat disimpulkan bahwa:

1) Instalasi Pengolahan Air Limbah (IPAL) yang dapat digunakan untuk daur ulang air limbah domestik menjadi air yang dapat dimanfaatkan kembali terdiri dari Grease Trap, Anaerobic Baffle Reactor (ABR) dan Aerobic Biofilter, dengan rincian sebagai berikut:

a. Grease Trap 1, dengan kapasitas 71,9 $\mathrm{m}^{3} /$ hari, memiliki efisiensi penyisihan minyak dan lemak sebesar $95 \%$

b. Grease Trap 2, dengan kapasitas $73,4 \mathrm{~m}^{3} /$ hari, memiliki efisiensi penyisihan minyak dan lemak sebesar $95 \%$ 
c. ABR - Aerobic Biofilter 1, dengan kapasitas 98,3 $\mathrm{m}^{3} /$ hari, memiliki efisiensi penyisihan BOD, COD, dan TSS berturut-turut adalah $99,5 \%, 98,8 \%$, dan 99\%

d. Aerobic Biofilter 2, dengan kapasitas 100,4 $\mathrm{m}^{3} / \mathrm{hari}$, memiliki efisiensi penyisihan BOD, COD, dan TSS berturut-turut adalah $98,7 \%, 96,3 \%$ dan $90 \%$

2) Biaya yang dibutuhkan untuk membangun serangkaian instalasi pengolahan dan Sistem Penyaluran Air Limbah (SPAL) tersebut adalah sebesar Rp 1.178.000.000,00

\section{UCAPAN TERIMA KASIH}

Penulis mengucapkan terimakasih kepada Jurusan Teknik Lingkungan, Dinas Tanah dan Bangunan Kota Surabaya, Badan Lingkungan Hidup Kota Surabaya, serta pengelola Rumah Susun Tanah Merah yang telah membantu penulis dalam penyusunan perencanaan.

\section{DAFTAR PUSTAKA}

[1] Anindita, Raras; Sudarno; Syafrudin. 2014. Pengaruh Konsentrasi Influen dan Kecepatan Upflow Terhadap Penyisihan BOD dan COD pada Pengolahan Air Limbah Domestik Artificial (Grey Water) Menggunakan Reaktor UASB. Program Studi Teknik Lingkungan, Fakultas Teknik, Universitas Diponegoro.

[2] Yusuf, Guntur. 2008. Bioremediasi Limbah Rumah Tangga dengan Tabel 2. Rencana Anggaran Biaya

\begin{tabular}{|c|c|c|c|}
\hline No & \multirow[t]{2}{*}{ Uraian RAB } & \multicolumn{2}{|r|}{ Harga } \\
\hline 1 & & $\mathrm{Rp}$ & $196,000,000.00$ \\
\hline 2 & Grease Trap 1 & $\mathrm{Rp}$ & $16,500,000.00$ \\
\hline 3 & Grease Trap 2 & $\mathrm{Rp}$ & $16,500,000.00$ \\
\hline 4 & ABR - Aerobic Biofilter 1 & $\mathrm{Rp}$ & $513,816,000.00$ \\
\hline 5 & Aerobic Biofilter 2 & $\mathrm{Rp}$ & $309,000,000.00$ \\
\hline 6 & $\begin{array}{l}\text { Bak Penampung Air } \\
\text { Olahan }\end{array}$ & $\mathrm{Rp}$ & $126,500,000.00$ \\
\hline & Total & $\mathbf{R p}$ & $1,178,316,000.00$ \\
\hline
\end{tabular}

Sistem Simulasi Tanaman Air. Jurnal Bumi Lestari. Vol. 8. No. 2.

[3] Sugito. 2012. Pengembangan Reaktor Biofilter Terpadukan dengan Teknologi Filtrasi untuk Mengolah air Limbah Domestik Menjadi Air Bersih. WAHANA. Volume 59. No. 2.

[4] Fatnasari, Hylda., Joni Hermana. 2010. Strategi Pengelolaan Air Limbah Permukiman di Bantaran Kali Surabaya. Jurusan Teknik Lingkungan, FTSP, Program Pascasarjana.

[5] Sasse, Ludwig. 1998. DEWATS Decentralised Wastewater Treatment in Developing Countries. Borda: Bremen

[6] Wongthanate, J., Mapracha N., Prapagdee B., Arunlertaree C. 2014. Efficiency of Modified Grease Trap for Domestic Wastewater Treatment. The Journal of Industrial Technology. Vol. 10.

[7] Said, Nusa Idaman., Satmoko Y. 2006. Rancang Bangun Instalasi Air Limbah Rumah Potong Hewan (RPH) Ayam dengan Proses Biofilter. JAI Vol. 2. No.1. 